\title{
Hartung, Olaf, Kleine deutsche Museumsgeschichte. Von der Aufklärung bis zum frühen 20. Jahrhundert
}

\section{Eva Knels}

\section{OpenEdition}

\section{Journals}

Édition électronique

URL : http://journals.openedition.org/ifha/6688

DOI : $10.4000 /$ ifha.6688

ISSN : 2198-8943

Éditeur

IFRA - Institut franco-allemand (sciences historiques et sociales)

Référence électronique

Eva Knels, « Hartung, Olaf, Kleine deutsche Museumsgeschichte. Von der Aufklärung bis zum frühen 20. Jahrhundert », Revue de l'IFHA [En ligne], Date de recension, mis en ligne le 01 janvier 2011, consulté le 22 septembre 2020. URL : http://journals.openedition.org/ifha/6688 ; DOI : https://doi.org/10.4000/ ifha.6688

Ce document a été généré automatiquement le 22 septembre 2020.

(C)IFHA 


\title{
Hartung, Olaf, Kleine deutsche Museumsgeschichte. Von der Aufklärung bis zum frühen 20. Jahrhundert
}

\author{
Eva Knels
}

1 L'histoire des musées est en plein essor depuis une quinzaine d'années. Une multitude de monographies et de cas d'étude ont vu le jour ces dernières années qui mettent en lumière l'histoire des collections, leurs organisation et arrangement, l'architecture des musées et ses acteurs ainsi que, dernièrement, les dynamiques transculturelles à l'œuvre au moment de leur formation et dans leur développement. Le propos du livre d'O.H. est de déceler les origines du « musée moderne » et de retracer les lignes de son développement en Allemagne tout au long du XIXe siècle. Si la période choisie est généralement considérée comme le Museumszeitalter (le siècle des musées) par excellence - avec d'importantes fondations de musées et la construction des bâtiments isolés et destinés à ce but -, l'auteur met l'accent sur les rapports et les relations réciproques des musées avec la société et ses conceptions de l'histoire. En s'appuyant sur des sources imprimées et la littérature spécialisée, O.H. parvient à faire une synthèse compacte qui présente l'histoire des musées comme un processus social, mené par divers groupes d'intérêts issus de la bourgeoisie, toujours imprégné d'une interprétation spécifique du passé ou motivé par de réelles intentions de former et de remodeler le présent, voire l'avenir.

2 L'ouvrage est divisé en trois parties : l'auteur ouvre son étude par un chapitre général sur la définition conceptuelle des musées et des acteurs qui y sont impliqués. Cette première partie, intitulée " Die Vielfalt der Museen » (« la diversité des musées ») lui permet de préparer son interprétation des musées et de leur évolution constante comme l'expression d'une culture d'histoire en transformation permanente (p. 16-25). Bien qu'O.H. y souligne les proximités et imbrications entre les différents types de musées, la deuxième partie de son ouvrage, " Museumstypen und Museumsgründer » 
("types de musées et fondateurs de musées »), propose une typologie des musées qui distingue sept catégories (musées d'art, musées des arts décoratifs, musées d'histoire culturelle, musées d'histoire régionale, musées ethnologiques, musées d'histoire naturelle et des techniques, musées d'histoire sociale et économique). Leur histoire, les conflits lors de leurs création, les crises de représentation et leurs transformations nécessaires au fil des années, en parallèle avec la société et leurs porte-paroles, sont mis en évidence. Les exemples illustratifs sont souvent choisis parmi des musées célèbres, comme le Germanisches Nationalmuseum à Nuremberg ou le Deutsches Museum à Munich. O.H. élargit, par ailleurs, son champ de référence à des institutions moins connues, comme le Heimatmuseum à Celle (p. 57-60). La troisième partie de l'ouvrage, intitulée «Ausblick» (" perspective ») est avec quatre pages (p. 108-111) bien trop courte pour être un vrai résumé des idées développées et ne peut qu'esquisser la crise des musées à la fin du XIXe siècle et les réformes en résultant.

3 Les points forts de ce petit livre sont certainement sa densité remarquable et la tentative aboutie de faire une synthèse de l'histoire des musées au XIXe siècle en relation avec les processus sociaux. Quelque peu regrettable est la renonciation à l'indication des dates de vie des personnages parfois peu connus ou des dates de formation des musées dans le texte. Hormis ce détail, le seul reproche qu'on pourrait faire à l'auteur est de n'avoir écrit sur ce sujet vaste et complexe qu'une " petite " histoire. La brièveté de l'ouvrage (111 pages de texte, 56 pages de notes, de bibliographie et d'index) ne permet ni de revenir sur les "vrais » débuts du musée moderne au XVIIIe siècle, ni de rendre compte des dynamiques transculturelles dans la formation et le développement des musées (ou de jeter des regards comparatifs sur les musées des pays voisins), ni de prolonger la perspective sur le présent.

Néanmoins, il s'agit d'une synthèse réussie qui s'adresse au débutant comme au chercheur avancé. Elle pourra certainement servir d'introduction pour les uns et d'objet de débat pour les autres. Ce petit volume donne au lecteur l'envie de se pencher plus profondément sur la passionnante histoire des musées et d'interroger notre rapport au passé (et au présent) dans les musées d'aujourd'hui.

Eva Knels (Technische Universität Berlin /

6 Deutsches Historisches Institut, Paris) 